Resumo

O conceito de sintoma é fundamental na psicanálise, orienta a sua práxis, demarca seus limites terapêticos e se tornou objeto de interesse a outros campos, como a educação. Apresentamos a evolução deste conceito nas obras de Freud e Lacan, oferecendo ao leitor um guia na trajetória desses autores e convidando-o a construir o seu próprio percurso. Miller (1987), Ocariz (2003) e Conde (2008) apresentaram o caminho para a leitura dos originais revelando que, ao longo da obra de Freud, o sintoma aparece como expressão de um conflito psíquico; mensagem do inconsciente e satisfação pulsional. Já Lacan, lendo Freud, apresenta o sintoma como mensagem; gozo e invenção.

Descritores: teoria psicanalitica; sofrimento psíquico; conceito de synthome, formações do inconsciente, tratamento anali tico.

\section{O CONCEITO DE SINTOMA NA PSICANÁLISE: UMA INTRODUÇÃO}

\author{
Aline Borba Maia \\ Cynthia Pereira de Medeiros \\ Flávio Fontes
}

O tema do sintoma é discutido em toda a Psicanálise por ser um conceito fundamental, que orienta a prática e demarca os limites terapêuticos desse campo de saber. No entanto, não só psicanalistas têm se interessado pelo mesmo. O mal-estar inerente ao campo da educação tem produzido, ao longo dos últimos anos, um diálogo profícuo com a Psicanálise, especialmente a partir das considerações produzidas por autores que problematizam a aproximação Psicanálise-Psicopegogia (Correa, 1990; Lajonquière, 1998; Mitsumori, 1997; Maia, 2010).

Psicanalista, psicóloga clínica, mestre em Psicologia pela Universidade Federal do Rio Grande do Norte.

- Psicanalista, Professora do Curso de Graduação e do Programa de Pós-Graduação em Psicologia da Universidade Federal do Rio Grande do Norte.

- $\square$ Psicólogo e Mestre em Psicologia pela Universidade Federal do Rio Grande do Norte (UFRN). 
Nesse sentido, um estudo aprofundado do conceito de sintoma no interior da psicanálise torna-se fundamental.

Considerando que a elaboração do referido conceito nas obras de Freud e Lacan não é linear e passa por diversas modificações, esse texto se constitui como um roteiro introdutório, que visa guiar o leitor na trajetória Freudo-lacaniana. Longe de pretender substituir a leitura dos originais, convidamos cada um a debruçar-se sobre os mesmos, construindo, assim, o seu próprio percurso.

No decorrer do texto apresentamos como, ao longo da obra de Freud, o sintoma aparece como expressão de um conflito psíquico, como mensagem do inconsciente e como satisfação pulsional, e que Lacan, lendo Freud, apresenta o sintoma como mensagem-metáfora; como gozo e como invenção-criação.

\section{O Sintoma na obra de Sigmund Freud}

Dias (2006), Quinet (1991), Kaufmann (1996), Machado (2003), Ocariz (2003), localizam o sintoma na origem da psicanálise, como fenômeno que convoca o ato freudiano de escutar um sentido onde antes o saber instituído afirmava só haver mentira. Esse posicionamento inaugural de Freud irá lançar as bases para a ética psicanalítica de escutar o sujeito em sua radical singularidade.
Optamos por uma leitura do conceito de sintoma em Freud orientada por três momentos da elaboração desse tema na obra do referido autor, como sugerido por Ocariz (2003): o conceito de sintoma antes de 1900; o conceito de sintoma entre 1900-1920, e o conceito de sintoma após 1920 .

\section{O conceito de sintoma antes de 1900}

No início de suas elaborações acerca do que afetava as histéricas, fortemente influenciado por suas experiências junto a Chacot e seu trabalho conjunto com Breuer, Freud defende que a histeria é o produto de um conflito psíquico gerado por um evento traumático que deixou marcas, mas que não é lembrado no estado de vigília.

Na obra conjunta, "Sobre o mecanismo psíquico de fenômenos histéricos: comunicação preliminar", Breuer e Freud afirmam que "os histéricos sofrem principalmente de reminiscências" (Freud, 1893/1996a, p. 43). Restos de eventos que haviam sido esquecidos retornam no corpo causando paralisias, dores inexplicáveis, cegueira.

Observando os casos descritos por Breuer e Freud nota-se que os eventos traumáticos que suas pacientes conseguem recordar sob hipnose e relacionar com seus sintomas são marcados por sentimentos de vergo- 
nha, menos-valia, rejeição. Diante de um pensamento que não é compatível com os ideais sociais e pessoais, as pacientes histéricas transformam o afeto ligado a essa idéia, retirando dela a excitação que a acompanha. Esse afeto liberto busca satisfação em outro objeto e encontra-a no sintoma.

Admitindo os limites do método hipnótico, não só em função da necessidade de uma habilidade especial do hipnotizador, que ele próprio reconhecia não ter, e de uma disposição especialmente dócil por parte dos pacientes, o que muitas vezes não acontecia, mas, sobretudo, em função do encobrimento da resistência, Freud abandona a hipnose e passa a utilizar a sugestão e a técnica da pressão como modos de impulsionar seus pacientes a relatarem conteúdos desagradáveis que eles insistiam em dizer que não lembravam. Como decorrência dessa abertura para a fala fora da hipnose, suas pacientes começam a falar do que as afeta (Freud, 1893/ 1996a).

Isto o leva a estabelecer, em 1904, a associação livre como a regra principal da psicanálise. A fala em transferência mostra-se mais eficiente na resolução dos sintomas, mesmo revelando as resistências de modo mais contundente (Freud, 1904[1903] /1996g).

Esta aparece quando o tratamento pode mexer no arranjo feito pelo paciente para manter fora de sua consciência as lembranças traumáticas. No entanto, o que se revela nos casos que

46 Estilos da Clínica, 2012, 17(1), 44-61 
Breuer e Freud apresentam é que quando a resistência cede, e as lembranças dolorosas são vivenciadas, os sintomas cessam, e a vida pode seguir com menos sofrimento.

Apresentando uma modificação na teoria da histeria corrente na época, Freud (1894/1996b) defende a divisão da consciência como um ato voluntário do paciente - o objetivo do paciente era se proteger de um afeto conflitivo, mas o que consegue produzir é a divisão da consciência.

Nesse momento de sua obra atribui a etiologia da histeria a "uma experiência sexual passiva antes da puberdade" (Freud, 1896/ 1996c, p. 151). Permitindo-se, portanto, aceitar que o trauma sexual estava na gênese de toda neurose, passa a supor que as cenas traumáticas de abusos de ordem sexual que lhe são relatadas por seus pacientes são verdade. O fato de os sintomas cessarem quando essas lembranças são relatadas lhe dá a confirmação de que são elas a causa das neuroses. Se não fossem verdadeiras, o que explicaria a "cura" dos sintomas?

No rascunho K, "As neuroses de defesa", enviado a Fliess em 1896, ele resume o curso tomado pela doença nas neuroses de recalcamento, que é, em geral, o mesmo: o paciente sofre uma experiência sexual prematura e traumática que deve ser recalcada; por força de contingências da vida desse paciente, lhe vem à consciência a lembrança de tal evento e há um esforço em recalcar, e assim surge um sintoma primário.

O estabelecimento do sintoma promove um período de relativa tranqüilidade psíquica, por contar com uma defesa eficiente, embora o paciente passe a conviver com a dor do sintoma primário. Posteriormente, as ideias recalcadas retornam e desse novo conflito surgem novos sintomas que "são os da doença propriamente dita: isto é, uma fase de ajustamento, de ser subjugado, ou de recuperação com uma mal formação" (Freud, 1896/1996d, p. 269).

Na carta 69, escrita a Fliess, em 1897, ele relata mudanças fundamentais em suas concepções de sintoma, neurose e sexualidade. A ideia de que a origem da histeria estava nos traumas sexuais relatados pelas pacientes, os quais, até então tomava como reais, encontrava limites, o que o leva a afirmar: "Não acredito mais em minha neurótica" (Freud, 1897/1996e, p. 308). Ele reconhece, então, que não se pode atribuir valor de realidade aos conteúdos inconscientes. O trauma, que antes tinha valor de verdade, se torna suposto ou inferido, o que o levará, posteriormente, a pensar na fantasia trau- 
mática - a cena tida como verdadeira pelo indivíduo, parte fundamental de sua realidade psíquica.

Nessa carta Freud também admite para Fliess que "o inconsciente nunca supera a resistência, então também abandonamos nossa expectativa de que o inverso aconteça no tratamento, a ponto de o inconsciente ser totalmente domado pelo consciente" (Freud, 1897/1996e, p. 310).

Reconhecer os relatos de suas pacientes como fantasias produtoras de sintomas, e reconhecer os limites do tratamento pela impossibilidade de "domar" o inconsciente e torná-lo consciente, faz Freud avançar e inaugurar a Psicanálise, tal como ela veio a ser conhecida posteriormente.

\section{O conceito de sintoma entre 1900-1920}

O ano de 1900 é lembrado como o ano de fundação da psicanálise, com a publicação de "A interpretação dos sonhos". Sempre na tentativa de compreender a origem dos sintomas Freud (1900/1996f) postula que os sonhos são fenômenos que deixam entrever os conteúdos inconscientes.

Neste texto afirma que os sonhos são realizações de desejos. Em alguns, essa realização é obvia, mas mesmo nos sonhos de angústia ela está presente, de forma distorcida. Essa distorção deve-se aos mecanis- mos de defesa, utilizados para manter encoberto o sentido do sonho, possibilitando ao sonhador a satisfação desejada, sem o desagrado de se dar conta de conteúdos inconvenientes.

Assim como os sonhos, o sintoma também é a realização de um desejo, que é sempre sexual. Este, no entanto, aparece em uma versão mais aceitável. Desse modo, o sujeito que sofre com seu sintoma não reconhece nele uma satisfação.

Nesse momento da obra freudiana, o sintoma é tomado como uma mensagem cifrada que encontra lugar para sua interpretação e elaboração no espaço analítico e que, ao mesmo tempo, provoca resistências ao seu tratamento.

O ciframento da mensagem concretizada pelo sintoma segue as mesmas leis de funcionamento dos outros fenômenos lacunares do inconsciente. Os conteúdos são submetidos às mesmas torções e versões que sofrem ao aparecer num sonho, ou incorrer num ato falho.

Embora advertido, como afirmamos anteriormente, da impossibilidade de domar o inconsciente, o trabalho analítico, neste período, visa colocar o inconsciente sob o domínio da consciência.

O tratamento psicanalítico consiste, então, na associação livre, através da qual se espera que o paciente revele tudo que passa por sua mente, sem reservas, certo que os pensamentos e lembranças estarão relacionados com o sintoma. 
Freud dedica a terceira parte das suas "Conferências introdutórias" a uma discussão da teoria geral das neuroses. Destas conferências, destacamos as que ele se refere de modo mais detido ao trabalho com os sintomas neuróticos, seu sentido e sua etiologia.

Na "Conferência XVII", Freud (1917[1916-17]/1996h) postula que os sintomas neuróticos têm um sentido que se estabelece de acordo com a vida dos indivíduos que dele padecem. Relaciona a neurose obsessiva a uma satisfação de desejo sexual, recalcada e protegida pela execução de rituais e explicita, mais uma vez, o conteúdo sexual que esses sintomas encobrem, na sua função de solução de compromisso, revelando e ocultando o conflito psíquico.

Nesse texto re-afirma sua conclusão de que parte (maior ou menor, dependendo do caso) do que seus pacientes relatam como cenas infantis que haveriam dado origem ao sintoma, não passam, muitas vezes, de fantasias e criações. O que havia sido o móvel inicial de sua teoria das neuroses - a experiência sexual real precoce - é, muitas vezes, uma fantasia tomada pelos próprios pacientes como verdade.

Diante dos sintomas, o tratamento consiste em encontrar o sentido além do aparente nonsense. Quando as lembranças voltam à tona no processo de análise e um sentido pode ser atribuído, as repetições sem fim encontram sua finalidade e os sintomas cessam.

Na “Conferência XXIII", Freud (1917[1916-17]/1996i) defende que os sintomas se formam quando

as duas forças que entraram em luta encontram-se novamente no sintoma e se reconciliam, por assim dizer, através do acordo representado pelo sintoma formado. É por esta razão, também, que o sintoma é tão resistente: é apoiado por ambas as partes em luta. (p. 361)

O sintoma, portanto, é um produto transfigurado pelo impulso de satisfação inconsciente da libido, e pela proteção exercida pelo recalque, atendendo num só momento a dois senhores, mantendo o equilíbrio entre essas instâncias, até que o sofrimento que o acompanha convoque o indivíduo a buscar outra solução.

Cabe lembrar que, até este momento da obra freudiana, estamos sob a regência dos princípios da realidade e do prazer que visam a manutenção da vida do sujeito e sua adaptação ao meio em que vive.

O que Freud vai encontrando em sua prática clínica é que os sintomas carregam em si uma satisfação que torna o tratamento difícil. Ele se dá conta que é com muita resistência que os pacientes 
abrem mão se seus sintomas e, ainda assim, não de modo total e definitivo. Essas conclusões o levam à elaboração de uma hipótese além da homeostase, do equilíbrio e do princípio de realidade e do prazer.

\section{O conceito de sintoma após 1920}

No ano de 1920 Freud publica "Além do princípio do prazer". Nesta obra, apresenta mudanças na sua concepção do aparelho psíquico e uma nova formulação acerca das forças que organizam o funcionamento deste aparelho. Aponta para uma pulsão de destruição que age no indivíduo, além das que estariam guardando a harmonia - princípio de realidade e princípio do prazer.

A meta de toda vida é a morte .... O inanimado está ali antes do vivo .... Em algum momento, por intervenção de forças que são para nós totalmente inimagináveis, suscitaram-se na matéria inanimada as propriedades da vida. A tensão assim gerada no material até então inanimado lutou por se libertar, assim nasceu a primeira pulsão, a de retornar ao inanimado. (Freud, 1920/1996j, p. 38)

Se, a princípio, Freud havia seguido sua formação médica e considerou o sintoma como sinal da quebra de harmonia na vida orgânica e psíquica das pessoas, sua experiência como analista vai evidenciando as dificuldades no trabalho com a resistência e a compulsão à repetição. "Sua

50 Estilos da Clínica, 2012, 17(1), 44-61 
prática clínica foi mostrando que a decifração dos significados não era suficiente" (Ocariz, 2003, p. 78). Alguns pacientes não conseguiam abrir mão de seus sintomas.

Assim, a partir de 1920 o conceito de sintoma passa a ter duas faces: o sintoma como efeito lacunar, como mensagem, passível de interpretação, e o sintoma como satisfação pulsional, que é o que resiste ao tratamento analítico.

Em "Inibições, sintomas e ansiedade" Freud (1926[1925]/19961) apresenta o sintoma como sendo "o verdadeiro substituto e derivativo do impulso reprimido ... continuamente renova suas exigências de satisfação e assim, obriga o ego, por sua vez, a dar o sinal de desprazer e a colocar-se em uma posição de defesa” (p. 103).

O sintoma surge como uma solução que visa re-estabelecer uma suposta homeostase que teria sido quebrada pelo conflito psíquico, e chega a cumprir sua função, no sentido de resolver o conflito, ao mesmo tempo que tem como produto uma satisfação que perturba. Temos o sintoma como sendo "uma resposta a uma satisfação insuportável” (Machado, 2003, p. 3).

Freud se vê diante da questão de como a satisfação de uma pulsão, mesmo que provisória, pode produzir desprazer. Isso é tratado em "Análise terminável e interminável" (1937/1996m), texto no qual expõe os limites da clínica analítica diante da impossibilidade de satisfação pulsional e, logo, da eliminação dos sintomas e da neurose. A longa duração de certas análises, a prevenção de futuros conflitos e a questão da cura são discutidas.

Diante da realidade do sintoma como solução de compromisso, mas também como satisfação pulsional, o que Freud entrevê é que a psicanálise não pode dar garantias. As tentativas de profixalia são infrutíferas.

Deparamo-nos com pessoas, por exemplo, a quem estaríamos inclinados a atribuir uma especial adesivisidade da libido. Os processos que o tratamento coloca em movimento nessas pessoas são muito mais lentos do que em outra, porque aparentemente, elas não podem decidir-se a desligar catexias libidinais de um determinado objeto e descolá-los para outro, embora não possamos descobrir nenhuma razão especial para essa lealdade catexial. (Freud, 1937/1996m, p. 258)

Um tipo de relação com a pulsão e um compromisso mais decidido em relação ao modo de lidar com a satisfação e dor do sintoma vão determinar as possibilidades do sucesso de um tratamento analítico. 


\section{O Sintoma na obra de Jacques Lacan}

A elaboração do conceito de sintoma aparece em diversos momentos da obra deste autor, passando por reformulações, ganhando novas nuances e guiando, até o final, sua noção de tratamento e cura. Miller (1987) e Ocariz (2003) afirmam que o tema do sintoma em Lacan pode ser compreendido de três modos: o sintoma como mensagem endereçada ao Outro $^{1}$, como gozo, e como produção e invenção do sujeito.

\section{O sintoma como mensagem-metáfora}

Os primeiros tempos do ensino de Lacan (de 1953-1963) são lidos por Miller (1987) como a época na qual existia uma prevalência dos textos e conceitos freudianos. Afirma, ainda, que, segundo o próprio Lacan, o texto que marca o início de seu ensino é "Função e campo da fala e da linguagem em psicanálise".

Nesse texto, escrito em 1953 e publicado em 1966, Lacan apresenta suas modificações da teoria da Linguística de Saussure, no que se refere ao significante, articulando esses conhecimentos com os textos freudianos.

A partir das categorias de Simbólico, Real e Imaginário apresenta o
Simbólico como ordenador da cultura, fundada pela linguagem. Nesse primeiro momento de seu ensino, evidenciando a prevalência do Simbólico, afirma: "é o mundo das palavras que cria o mundo das coisas" (Lacan, 1998a, p. 277). O que é regido pelo instinto e pelas informações filogenéticas nos animais, no ser humano é construído e ordenado pela cultura. Isso faz com que o ser humano tenha que se encontrar com referências culturais para dar conta da sua relação com a alimentação, com o sexo e encontrar seu lugar no grupo social no qual está inserido.

O imaginário diz respeito à relação entre semelhantes, de um indivíduo com o outro, especular; e o Real nessa época aparece como o que está fora da experiência analítica.

Ao longo de sua obra, em diversos momentos Lacan vai dando ênfase a cada uma dessas categorias. No seu primeiro ensino (1953-1963) o simbólico está no plano principal de suas elaborações teóricas e da sua concepção de psicanálise, como pode ser observado no trecho a seguir: "quer se pretenda agente de cura, de formação ou de sondagem, a psicanálise dispõe de apenas um meio: a fala do paciente" (Lacan, 1998b, p. 248). Essa fala, que a princípio é direcionada ao analista como é a qualquer outro ao longo da vida do sujeito, porta sua verdade, e só poderá emergir quando escutada de um modo particular. A esse respeito afirma: "a arte do analista deve consistir 
em suspender as certezas do sujeito até que se consumam suas últimas miragens. E é no discurso que deve escandir-se a resolução delas" (Lacan, 1998a, p. 253).

A fala vazia, endereçada ao semelhante, poderá ser transformada em fala plena, através da qual o sujeito poderá encontrar um novo modo de lidar com o seu sintoma. Este sintoma é tomado por Lacan, nesse momento, como "o significante de um significado recalcado da consciência do sujeito. Símbolo escrito na areia da carne e no véu de Maya, ele participa da linguagem pela ambigüidade semântica que já sublinhamos em sua constituição" (Lacan, 1998a, p. 282).

O sintoma faz parte do jogo de significantes e, desse modo, é ordenado por suas leis. Nesse sentido "todo fenômeno analítico, todo fenômeno que participa do campo analítico, da descoberta analítica, daquilo com que lidamos no sintoma e na neurose, é estruturado como linguagem" (Lacan, 1988, p. 192).

Assim, trata-se, pela palavra, de desvelar o sentido que essa mensagem, o sintoma, explicita e esconde. A esse respeito afirma que, diferentemente do signo, o sintoma só é interpretado na ordem do significante.

O significante só tem sentido por sua relação com outro significante. É nessa articulação que reside a verdade do sintoma. $\mathrm{O}$ sintoma tinha um ar impreciso de representar alguma irrupção da verdade. A rigor ele é verdade, por ser talhado na mesma maneira que ela é feita. (Lacan, 1998b, p. 235) 
A verdade do sintoma é uma verdade construída. Numa análise busca-se, portanto, que a palavra plena surja por meio da transferência e do trabalho de retificação subjetiva, no qual o sujeito pode se implicar com aquilo mesmo que o faz sofrer, se dando conta de sua parte em seu sintoma, assumindo sua história.

No texto "Instância da letra no inconsciente ou a razão desde Freud" a cadeia significante é apresentada como o que ordena o humano. Lacan apresenta a mudança que faz no signo linguístico de Saussure e relaciona a condensação e o deslocamento freudianos, modos da mensagem que o sintoma comporta, como metáfora e metonímia. O sintoma como metáfora aponta para outro sentido, é um significante em relação a outro significante: "do mais simples ao mais complexo dos sintomas, a função significante revela-se preponderante, por surtir efeito neles já no nível do trocadilho" (Lacan, 1998c, p. 448).

Nesse sentido, o sintoma está no registro do simbólico, retendo um saber que o sujeito se recusa a reconhecer:

O mecanismo de duplo gatilho da metáfora é o mesmo em que se determina o sintoma no sentido analítico. Entre o significante enigmático do trauma sexual e o termo que ele vem substituir numa cadeia significante atual passa a centelha que fixa num sintoma - metáfora em que a carne ou a função são tomadas como elemento significante - a significação inacessível ao sujeito consciente onde ele pode se resolver. (Lacan, 1998c, p. 522)

Não caberia nem seria possível ao analista revelar ao sujeito o significado desse recalcado que retorna, mas é possível, ao sujeito, construir sua verdade num processo analítico.

Em O seminário, livro 5: as formações do inconsciente, Lacan (1998d) faz uma retomada das formulações freudianas em "Além do princípio do prazer" para falar da insistência do sintoma e seu caráter de satisfação paradoxal, tocando em pontos que ele aprofunda posteriormente em sua obra quando formula o sintoma como gozo.

\section{O sintoma como modo de gozo}

Como afirmamos anteriormente, nos primeiros seminários de Lacan há uma primazia do Simbólico: o inconsciente está estruturado como uma linguagem, e o sintoma é uma metáfora. Com o avan-

54 Estilos da Clínica, 2012, 17(1), 44-61 
ço de sua clínica, suas formulações teóricas vão sendo reorientadas em direção ao Real ${ }^{2}$ como o que resiste a qualquer significação.

O sintoma é, no começo, "o mutismo do sujeito suposto falante. Se ele fala, está curado de seu mutismo, evidentemente" (Lacan, 1991, p. 18). O sintoma tem algo a dizer - a verdade do sujeito. Se o sujeito se dispõe a falar seu sintoma pode ser recriado. Como a univocidade está fora da linguagem humana existem múltiplos significados que podem ser recriados para o sintoma.

No entanto, existe um limite. Freud havia se deparado com o mesmo e é esse limite que ele procurava tratar em seu texto "A análise terminável e interminável". Há um resto que sobra como incurável da pulsão que sempre se satisfaz.

Lacan identifica que existe nesse limite um sofrimento e uma satisfação. Ele se refere ao sintoma como sentido na tentativa de tamponamento da falta fundamental, do fora do sentido, que a língua e o significado não conseguem recobrir. $\mathrm{O}$ "sintoma pode ser compreendido como resultado de uma estrutura marcada por uma falta, representando a verdade que aponta para essa falta inerente. Aí residiria o aspecto 'incurável' do sintoma" (Conde, 2008, p. 67).

A falta estrutural do Outro da linguagem precisa ser tratada pelo sujeito que, para isso, faz uso do sintoma.
É interessante notar que o sujeito se sustenta não em um sofrimento, mas em uma satisfação. Por isso, para o sujeito é tão difícil abrir mão do sintoma, pois ele manifesta, mesmo que de modo invertido, a sua via de contentamento e sustentação. (Conde, 2008, p. 64)

Esse núcleo duro, intocável pelo sentido é o que Lacan estabelece nesse segundo momento do seu ensino (1964-1974) como o gozo do sintoma.

Desde $O$ seminário, livro 1: os escritos técnicos de Freud (1986) aponta, com Freud, que há no sintoma uma satisfação desviada. Em O seminário, livro 14: a lógica do fantasma (2008), o gozo é definido como

essa alguma coisa que tem relação com o sujeito, enquanto confrontamento com esse buraco deixado num certo registro de ato questionável, o do ato sexual. Ele é, esse sujeito, suspenso por uma série de modos ou de estados que são de insatisfação. Eis o que por si só, justifica a introdução do termo de gozo, que, do mesmo modo, é o que, a todo instante e - especialmente no sintoma - se propõe a nós como indiscernível desse registro da satisfação. Pois que, a todo instante, para nós, o problema é saber como um nó, que não se suporta senão de mal-estar e de sofrimento, é justamente isso pelo qual se manifesta a instância da satisfação suspensa: propriamente isso onde o sujeito se sustenta quando tende para essa satisfação. (Lacan, 2008, p. 381)

Nesse sentido, o gozo não coincide com prazer, mas é um modo de satisfação que leva o sujeito em direção ao seu pior: a pulsão de morte. $\mathrm{O}$ que o sujeito sente é um sofrimento intolerável que, paradoxalmente, é 
uma satisfação. O gozo, diferentemente do prazer, não circula, não encontra satisfação a não ser voltando sempre ao mesmo lugar, repetindo. "O gozo é a satisfação da pulsão de morte" (Ocariz, 2003, p. 126).

Em O seminário, livro 17: o avesso da psicanálise, Lacan (1993) afirma que: "A vida é o conjunto de forças que resiste à morte .... Na experiência analítica se faz presente essa tendência de retorno ao inanimado ... pois o caminho para a morte nada mais é do que aquilo que se chama gozo" (p. 16).

O sintoma porta uma satisfação que não se pode parar de tentar buscar, e que, ao mesmo tempo, não se alcança. Por ser a via privilegiada de satisfação do sujeito "o sintoma pode desvelar a estrutura de sua subjetividade. O modo como os significantes se articulam em torno desse paradoxo contentamento-problema vai dar as pistas de como está estruturada tal subjetividade" (Conde, 2008, p. 65). Ao desvelar a estrutura do sujeito, o sintoma revela-se como a solução singular que o sujeito encontrou para dar conta de seu lugar no mundo dos falantes.

O tratamento analítico não visa aqui o franqueamento do recalque, para que o sujeito tenha acesso pleno à sua verdade, já que essa verdade é não-toda. Trata-se, nesse momento, de promover uma "elaboração de saber que produz uma transformação no sintoma e, como efeito sobre o real, uma transformação do gozo.

56 Estilos da Clínica, 2012, 17(1), 44-61 
Modificação que não é supressão, mas que dá um lugar a um resto de gozo que é particular de cada um" (Kruger, 1998, p. 106).

\section{O sintoma como criação/invenção de um sujeito}

O sintoma é o trabalho de todo sujeito para dar conta do Real. Assim, "não deve ser dissociado do sujeito, algo que deve ser modificado, mas não arrancado do sujeito, por ser fundamental em sua estrutura" (Ocariz, 2003, p. 137).

Segundo essa compreensão, os sintomas já são tentativas de tratar o Real, modular o gozo, que podem ser mais ou menos danosas para o sujeito. A perspectiva do tratamento analítico, nesse momento da elaboração lacaniana, não visa à eliminação dos sintomas, mas a ajudar o sujeito a encontrar uma nova forma de lidar com seu sintoma, com aquilo que o constitui.

Em seu último ensino, Lacan localiza o sintoma como invenção, criação do sujeito. O "sintoma não é uma palavra, uma metáfora na qual a significação é função do significante (definição de metáfora), mas é uma função da letra, que não é um significante" (Ocariz, 2003, p. 102).

No seminário 23 há uma ênfase ainda maior na passagem teórica da linguística para a topologia e Lacan vai recorrer aos textos de James Joyce como um modo de exemplificar o que é um sinthoma. A diferença na grafia serve para mostrar que o sinthoma não é mórbido. Aqui ele se torna mais um numa série: simbólico, real e imaginário, sendo o sinthoma o que vai amarrar os três.

Neste seminário, se refere à boa maneira de lidar com o sinthoma "A boa maneira é aquela que, por ter reconhecido a natureza do sinthoma, não se priva de usar isso logicamente, isto é, de usar isso até atingir seu real, até se fartar" (Lacan, 2007, p. 16). Ou seja, tratase de saber fazer com o sinthoma de modo que o sujeito possa se valer dele, e não mais estar submetido. Isso depende de o sujeito se desprender da idéia de que o Outro goza de seu sintoma, que encare a falta no Outro.

O sinthoma está no lugar onde falha o nó. O sinthoma denota a falha à qual faz suplência. Nesse sentido "é com o sinthoma que temos de nos haver na própria relação sexual" (Lacan, 2007, p. 98). Para chegar ao sinthoma o sujeito precisa ter se havido com a falta no 
Outro e ter passado pelo sintoma mórbido, pela queixa, para se dar conta de sua implicação, de como o sinthoma que porta lhe é caro.

O final de uma análise consiste em um "saber fazer com o sinthoma" precisamente ali onde a relação sexual não se inscreve e o simbólico não alcança, onde as palavras não são suficientes.

THE CONCEPT OF SYMPTOM IN PSYCHOANALYSIS: AN INTRODUCTION

\section{Abstract}

The concept of symptom is fundamental to psychoanalysis, guides its practice, establishes its therapeutic limits and has become an object of interest to other fields of knowledge, such as Education. We present the evolution of this concept in the works of Freud and Lacan in order to offer the reader a guide through the theoretical trajectory of those authors, inviting the reader to make its own path. Miller (1987), Ocariz. (2003) and Conde (2008), showed us how to analyze the works of Freud and Lacan revealing that along the works of Freud, the symptom appears as an expression of a psychic conflict, a message from the unconscious and instinctual satisfaction. Lacan, in his reading of Freud, presents the symptom as message, joy (joussaince) and invention.

Index terms: psychoanalytic theory; psychological distress; concept of synthome; unconscious formations; psychoanalytical treatment.

EL CONCEPTO DE SINTOMA EN PSICOANALLISIS: UNA INTRODUCCIÓN

\section{Resumen}

El concepto de sintoma es fundamental en la psicoanálisis, orienta su práctica, marca sus limites terapéuticos y se convirtió en objeto de interés para otros campos, como la educación. Presentamos la evolución de este concepto en las obras de Freud y Lacan, ofreciendo al lector un guía en la trayectoria de estos autores e invitando-lo a construir su propia ruta. Miller (1987), Ocariz (2003) y Conde (2008), nos mostraran el camino para la lectura de los originales revelando que, a lo largo de la obra de Freud, el sintoma aparece como una expresión del conflicto psíquico, mensaje del inconsciente e satisfacción pulsional. Ya Lacan, en su lectura de Freud, presenta el sintoma como una mensaje, como goce y como invención.

Palabras clave: teoría psicoanalitica; sufrimiento psicológico; concepto de synthome, formaciones del inconsciente; tratamiento psicoanalitico.

\section{REFERÊNCIAS}

Conde, H. (2008). O sintoma em Lacan. São Paulo: Escuta.

Correa, J. (1990). De Freud a Piaget: algumas considerações acerca da noção de subjetividade. Arquivos Brasileiros de Psicologia, 42(2), 58-65.

Dias, M. G. L. V. (2006). O sintoma: de Freud a Lacan. Psicologia em Estudo, 11(2), 399405.

Freud, S. (1996a). Sobre o mecanismo psíquico dos fenômenos histéricos: comunicação preliminar. In S. Freud, Edição standard brasileira das obras psicológicas completas de Sigmund Freud (J. Salomão, trad., Vol. 2, pp. 39-53). Rio de Janeiro: Imago. (Trabalho original publicado em 1893)

Freud, S. (1996b). As neuropsicoses de defesa. In S. Freud, Edição standard brasileira das obras psicológicas completas de Sigmund Frend (J. Salomão, trad., Vol. 3, pp. 50-66). Rio de Janeiro: Imago. (Trabalho original publicado em 1894)

Freud, S. (1996c). Hereditariedade e etiologia das neuroses. In S. Freud, Edição standard brasileira das obras psicológicas completas de Sigmund Freud (J. Salomão, trad., Vol. 3, 


\section{Dossiê}

pp. 139-155). Rio de Janeiro: Imago. (Trabalho original publicado em 1896)

Freud, S. (1996d). Rascunho K. As neuroses de defesa. In S. Freud, Edição standard brasileira das obras psicológicas completas de Sigmund Freud (J. Salomão, trad., Vol. 1, pp. 267-276). Rio de Janeiro: Imago. (Trabalho original publicado em 1896)

Freud, S. (1996e). Carta 69 de 21 de setembro de 1897. In S. Freud, Edição standard brasileira das obras psicológicas completas de Sigmund Freud (J. Salomão, trad., Vol. 1, pp. 309-311). Rio de Janeiro: Imago. (Trabatho original publicado em 1897)

Freud, S. (1996f). A interpretação dos sonhos (continuação). In S. Freud, Edição standard brasileira das obras psicológicas completas de Sigmund Freud (J. Salomão, trad., Vol. 5, pp. 371-655). Rio de Janeiro: Imago. (Trabalho original publicado em 1900)

Freud, S. (1996g). O método psicanalítico de Freud. In S. Freud, Edicão standard brasileira das obras psicológicas completas de Sigmund Freud (J. Salomão, trad., Vol. 7, pp. 233240). Rio de Janeiro: Imago. (Trabalho original publicado em 1904[1903])

Freud, S. (1996h). Conferência XVII. O sentido dos sintomas. In S. Freud, Edição standard brasileira das obras psicológicas completas de Sigmund Freud (J. Salomão, trad., Vol. 16, pp. 265-279). Rio de Janeiro: Imago. (Trabalho original publicado em 1917[1916-17])

Freud, S. (1996i). Conferência XXIII Os caminhos da formação dos sintomas. In S. Freud, Edição standard brasileira das obras psicológicas completas de Sigmund Freud (J. Salomão, trad., Vol. 16, pp. 361-378). Rio de Janeiro: Imago. (Trabalho original publicado em 1917[1916-17])

Freud, S. (1996j). Além do princípio do prazer. In S. Freud, Edição standard brasileira das obras psicológicas completas de Sigmund Freud (J. Salomão, trad., Vol. 18, pp. 1175). Rio de Janeiro: Imago. (Trabalho original publicado em 1920)

Freud, S. (19961). Inibições, sintomas e ansiedade. In S. Freud, Edição standard brasi- 
leira das obras psicológicas completas de Sigmund Freud (J. Salomão, trad., Vol. 20, pp. 81-171). Rio de Janeiro: Imago. (Trabalho original publicado em 1926[1925])

Freud, S. (1996m). Análise terminável e interminável. In S. Freud Edição standard brasileira das obras psicologicas completas de Sigmund Freud (J. Salomão, trad., Vol. 23, pp. 225-270). Rio de Janeiro: Imago. (Trabalho original publicado em 1937) Quinet, A. (1991). As $4+1$ condições da análise. Rio de Janeiro: Jorge Zahar.

Kaufmann, P. (1996). Dicionário enciclopédico de psicanálise. Rio de Janeiro: Jorge Zahar.

Kruger, F. (1998). Gozar do sintoma. In Fundação do Campo Freudiano, O sintoma-charlatão (pp. 101-109). Rio de Janeiro: Fundação do Campo Freudiano/ Jorge Zahar.

Lacan, J. (1982). O seminário, livro 20: mais, ainda, 1972-1973. Rio de Janeiro: Jorge Zahar.

Lacan, J. (1986). O seminário, livro 1: os escritos técnicos de Freud, 1953-1954. Rio de Janeiro: Jorge Zahar.

Lacan, J. (1988). O seminário, livro 3: as psicoses, 1955-1956. Rio de Janeiro: Jorge Zahar.

Lacan, J. (1991). O seminário, livro 11: os quatro conceitos fundamentais da psicanálise, 1964. Rio de Janeiro: Jorge Zahar.

Lacan, J. (1993). O seminário, livro 17: o avesso da psicanálise, 1969-1970. Rio de Janeiro: Jorge Zahar.

Lacan, J. (1998a). Função e campo da fala e da linguagem em psicanálise. In J. Lacan, Escritos (V. Ribeiro, trad., pp. 238-324). Rio de Janeiro: Jorge Zahar.

Lacan, J. (1998b). Do sujeito enfim em questão. In J. Lacan, Escritos (V. Ribeiro, trad., pp. 229-237). Rio de Janeiro: Jorge Zahar.

Lacan, J. (1998c). A instância da letra no inconsciente ou a razão desde Freud. In J. Lacan, Escritos (V. Ribeiro, trad., pp. 496-590). Rio de Janeiro: Jorge Zahar.

Lacan, J. (1998d). O seminário, livro 5: as formações do inconsciente, 1957-1958. Rio de Janeiro: Jorge Zahar.

Lacan, J. (2007). O seminário, livro 23: o sinthoma, 1975-1976. Rio de Janeiro: Jorge Zahar.

Lacan, J. (2008). O seminário, livro 14: a lógica da fantasia, 1966-1967. Recife, PE: Centro de Estudos Freudianos do Recife.

Lajonquière, L. (1998). (Psico) pedagogia, psicanálise e educação. Uma aula introdutória. Estilos da Clínica, 1(1), 120-134.

Machado, O. (2003). O sintoma freudiano e o gozo. Cadernos de Psicanálise, 19(22), 157-178.

Maia, A. (2010). O conceito de sintoma na Psicanálise e na Psicopedagogia: do que se trata? Dissertação de mestrado, Universidade Federal do Rio Grande do Norte, Natal.

Miller, J-A. (1987). O percurso de Lacan. Rio de Janeiro: Jorge Zahar.

Mitsumori, N. (1997). Uma leitura crítica de Alicia Fernánder. Dissertação de mestrado, Universidade do Estado de São Paulo, São Paulo.

Ocariz, M. (2003). O sintoma e a clínica psicanalítica. São Paulo: Via Lettera.

Roudinesco, E. \& Plon, M. (1998). Dicionário de psicanálise. Rio de Janeiro: Jorge Zahar. 


\section{Dossiê}

\section{NOTAS}

1 "Termo utilizado por Jacques Lacan para designar um lugar simbólico - o significante, a lei, a linguagem, o inconsciente, ou ainda, Deus - que determina o sujeito, ora de maneira externa a ela, ora de maneira intra-subjetiva em sua relação com o desejo. Pode ser simplesmente escrito com letra maiúscula, opondo-se então a um outro com letra minúscula definido como outro imaginário ou lugar da alteridade especular" (Roudinesco \& Plon, 1998, p. 558).

2 O conceito de Real sofre modificações ao longo da obra de Lacan passando de realidade em si, o que está fora da experiência analítica (1953a/1998), o que faz obstáculo à cadeia significante $(1957 / 1998)$, até ser formalizado como o impossível de ser simbolizado, o que não cessa de não se inscrever (1972-73/1982).

alinebmaia@gmail.com cynthiamedeiros@yahoo.com flavioffontes@hotmail.com

Recebido em marco/ 2011. Aceito em maio/ 2011. 